\title{
ANÁLISE DO USO E OCUPAÇÃO DO SOLO NO MUNICÍPIO DE GARRUCHOS - RS ATRAVÉS DE SENSORIAMENTO REMOTO
}

\author{
Lucas Krein Rademann $^{(a)}$, Richard Kohler Marczewski ${ }^{(\mathrm{b})}$, Romario Trentin ${ }^{(\mathrm{c})}$ \\ (a) Departamento de Geocências/ Universidade Federal de Santa Maria, lucasrademann@ yahoo.com; \\ ${ }^{(b)}$ Departamento de Geociências/ Universidade Federal de Santa Maria,richar_kohler@ hotmail.com; \\ ${ }^{(c)}$ Departamento de Geociências/Universidade Federal de Santa Maria, romario.trentin@gmail.com.
}

\section{Eixo: GEOTECNOLOGIAS E MODELAGEM ESPACIAL DA GEOGRAFIA FÍSICA}

\begin{abstract}
Resumo
Em vista da importância da análise do uso do solo de uma unidade territorial, este trabalho tem como objetivo fazer o mapeamento e análise do uso e ocupação do solo do município de Garruchos, através do uso de imagens de satélite e de SIG, gerando assim dados de potencialidades e de como estão especializadas as diferentes formas de uso da terra dentro do município. Para a análise do uso do solo foram utilizadas imagens LANDSAT 8 e processadas no SIG ArcGIS 10.2. Constatou-se que o município possui um predomínio de Campos que são caracterizados pela vegetação nativa da região onde é realizado o pastoreio do gado. Conclui-se que o uso de SIG e de geotecnologias facilita a análise do uso do solo que é uma importante ferramenta de diagnóstico para ser utilizado na gestão do município.
\end{abstract}

Palavras-Chave: Uso e Ocupação do Solo; SIG; Cartografia Ambiental; Garruchos - RS;

\section{Introdução}

Devido à intensa antropização do espaço, surgem diversas formas de uso e ocupação do meio, causando variados impactos ambientais e sociais. Em vista disto, têm-se desenvolvido diversas ferramentas de análise do uso do solo através de sensoriamento remoto e Sistemas de Informação Geográfica (SIG), para assim compreender o uso do solo e planejar o ordenamento territorial.

Portanto Souza e Reis (2011) destacam que "o mapeamento do uso dos solos em uma determinada região é importante pela necessidade de compreender a organização do espaço e suas mudanças, uma vez que o meio ambiente sofre transformações causadas pelos processos naturais e, sobretudo pelas ações antrópicas.”. Ainda Souzaet al (2014) destaca que para um município, ter o conhecimento da cobertura e do uso que se faz da terra em seu interior, permite o desenvolvimento de técnicas e projetos que visem um melhor planejamento e gestão do ambiente em questão.

O município de Garruchos possui uma área total de $803,7636 \mathrm{~km}^{2}$ e está localizado na região Oeste do estado do Rio Grande do Sul (Figura 1) fazendo limite com os municípios de São Borja, Santo Antônio das Missões e São Nicolau, bem como faz fronteira com a Argentina. Esta região se caracteriza principalmente pela criação de gado e de ovinos nas áreas de campo nativo, devido a sua vegetação rasteira e propícia para o pastoreio que é históricamente utilizada para estes fins. 


\section{Localização do Município de Garruchos - RS}
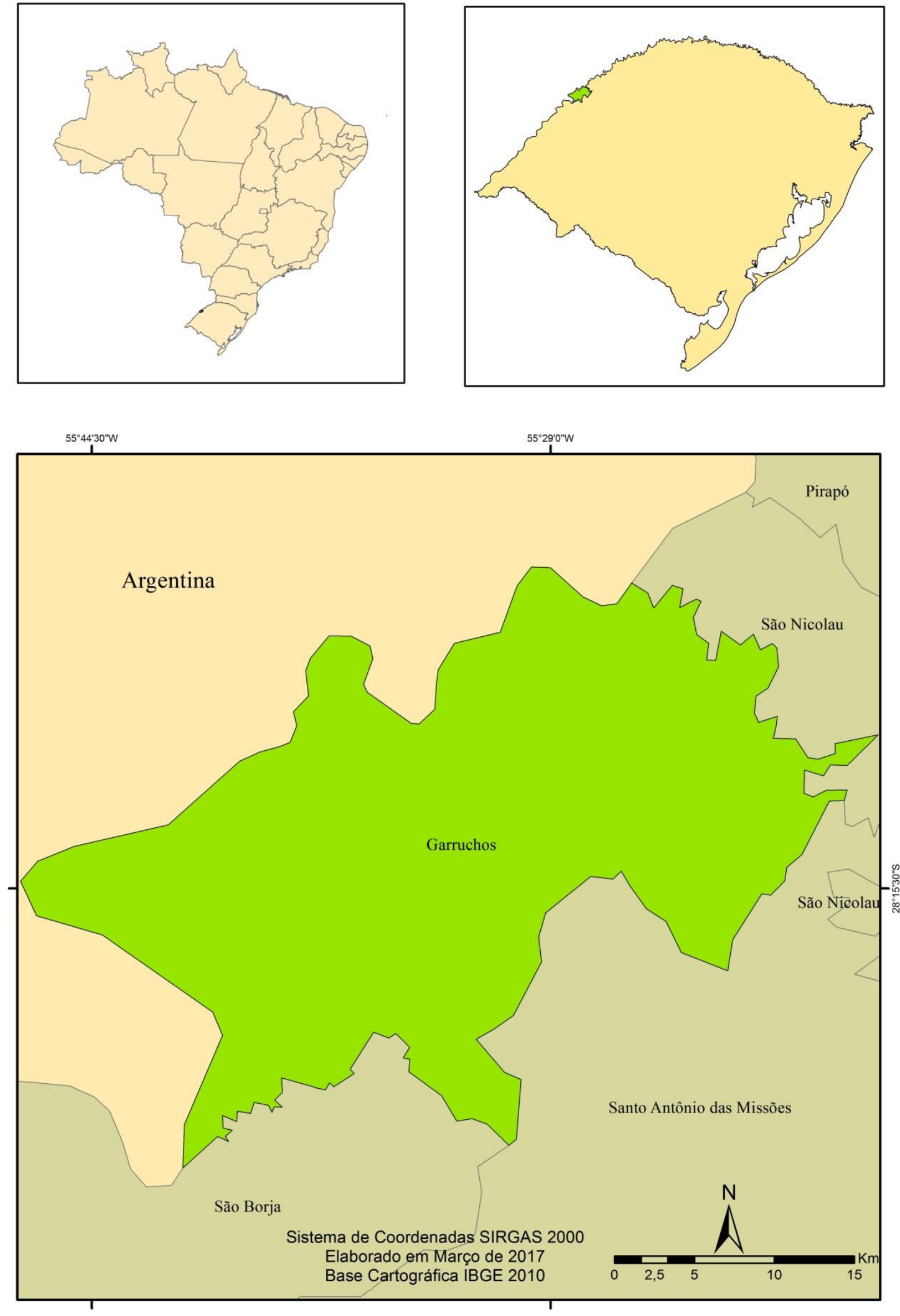

Figura 1 - Mapa de Localização do Município de Garruchos - RS; 
Portanto este trabalho tem como objetivo fazer o mapeamento e análise do uso e ocupação do solo do município de Garruchos, através do uso de imagens de satélite e de SIG. Gerando assim dados de potencialidades e de como estão especializadas as diferentes formas de uso da terra dentro do município.

\section{Metodologia}

O mapa de uso e ocupação foi feito através de imagens de satélite com o Sensor OLI do LANDSAT 8. As imagens foram escolhidas de acordo com a cobertura de nuvens do local e são datadas de $31 / 10 / 2016$. A orbita do satélite que cobre o município é a 224 e o ponto é 80 , sendo que as imagens foram retiradas do site glovis.usgs.gov.

Para a classificação do solo foi utilizada a ferramenta "ImageClassification" do SIG (Sistema de Informação Geográfica) ArcGis 10.2 desenvolvido pela ESRI. Foram coletadas amostras de 6 classes distintas, sendo essas Campos, Lavouras, Áreas Urbanas, Florestas, Água e Solo Exposto que posteriormente foi unido com a classe de Lavouras pelo fato do solo exposto representar áreas de lavouras onde há o pousio do solo nos períodos de entressafra. Então, foi efetuada uma classificação supervisionada através das imagens LANDSAT 8 através do método Maxver.

Para a elaboração do mapa de localização foi utilizado do mesmo SIG com base no banco de dados disponibilizado pelo IBGE no senso de 2010.

\section{Resultados}

Dos resultados encontrados foi possível identificar que o município de Garruchos possui cinco classes de uso do solo, sendo elas, lavouras, onde há o plantio de soja na porção de colinas do município e de arroz nas partes mais baixas, campos, que é caracterizado pela vegetação nativa da região de gramíneas, e também áreas de pecuária de gado e de ovinos, florestas que são áreas de capões e de mata, águas, que representa os reservatórios do município para dessedentação animal, e de rios, como o Rio Uruguai que faz divisa com a Argentina, e ainda o meio urbano que é caracterizado pela sede de Garruchos.

A Figura 2 traz o mapa de uso do solo no município de Garruchos aonde conseguimos ver a distribuição do uso e ocupação do solo na área de estudo. 


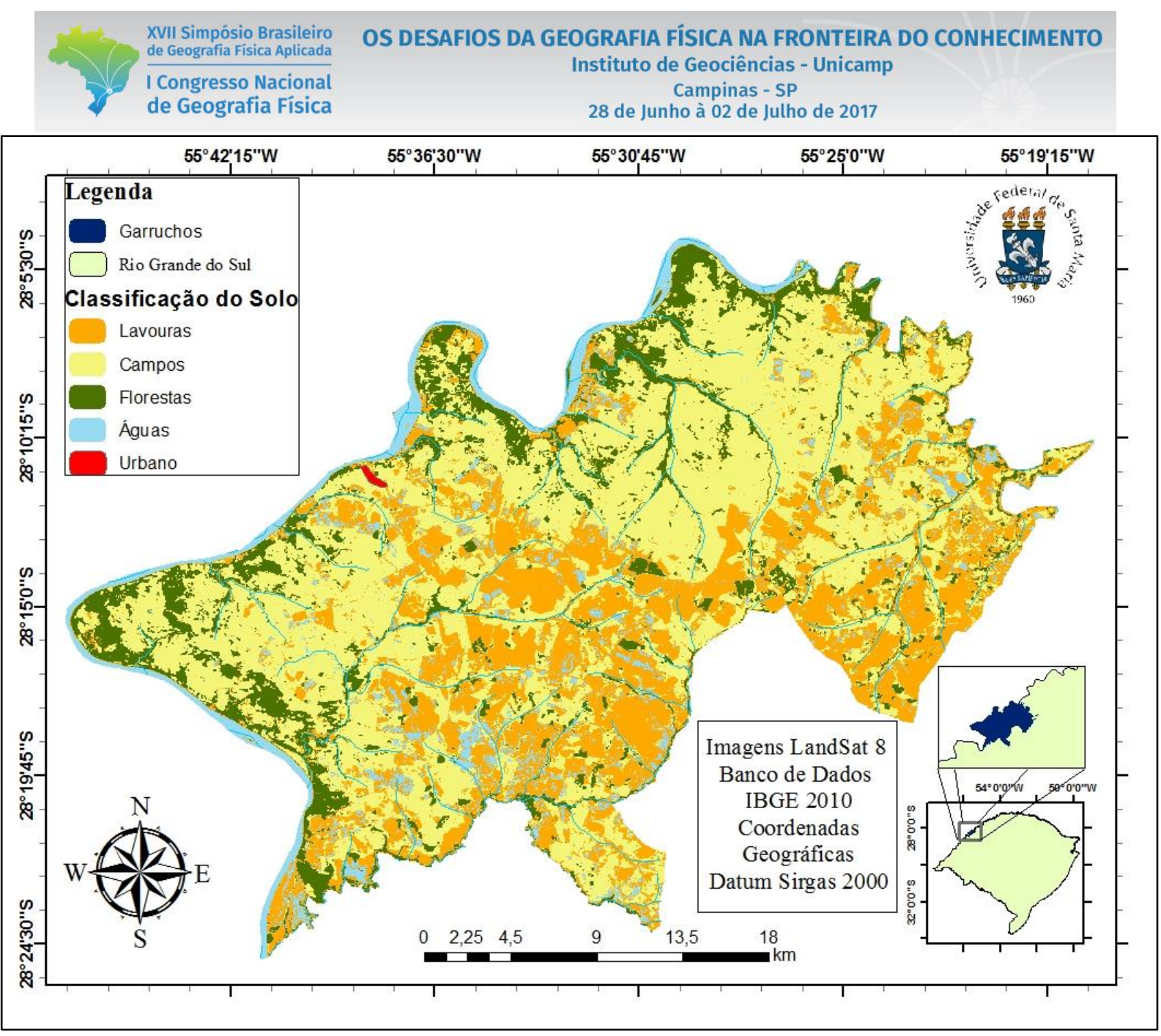

Figura 2 - Mapa de Uso do Solo no Município de Garruchos - RS;

A classe dos campos é a predominante em Garruchos e estão distribuídos da porção sudoeste até á nordeste, e são correspondentes a 49\% da área total, ou seja, 38.983,30 Ha. Com isso conseguimos verificar que o município possui uma grande atividade de pecuária que historicamente é desenvolvida na Região Oeste do estado do Rio Grande do Sul.

As lavouras em sua maioria ocupam a região centro-sul e leste no município e correspondem a $23.908,20 \mathrm{Ha}$ o equivalente a trinta por cento da região total do município. Estas lavouras segundo o Censo Agropecuário do IBGE de 2006 são principalmente dos cultivares de arroz, soja e milho.

Ainda podemos verificar que as áreas referentes a florestas se concentram em sua maioria na porção Norte Oeste do município na qual é a divisa com a argentina e que margeia o rio Uruguai, caracterizadas por matas ciliares e matas de capões, ao total são 10.653,50 Hade florestas o que equivale a treze por cento da área.

Já a classe das águas se concentra em grande parte no decorrer do rio Uruguai devido a este ser um dos grandes rios do Estado do Rio Grande do Sul fazendo parte das três maiores bacias de captação. São 6.405,62 Ha de águas em todo o município o que equivale a oito por cento da área total. 
Por fim, a classe da Área Urbana se concentra na sede do município, na porção Oeste da área de estudo às margens do Rio Uruguai e representa uma área de 51,06 Ha.

\section{Considerações Finais}

Portanto podemos concluir que Garruchos é um município de características agrárias, com o principal uso da terra de campos nativos que são utilizados para a criação de gado e ovinos de maneira extensiva. Ainda podemos ressaltar o uso do solo voltado para a agricultura na classe de Lavouras, sendo outra característica marcante do município.

Ainda cabe salientar que as geotecnologias, o uso de sensoriamento remoto e de SIGs torna a análise espacial mais rápida e precisa desta forma auxiliando na compreensãoda organização do espaço. Desta forma o presente trabalho pode ser utilizado para a gestão do município e seu ordenamento territorial.

\section{Bibliografia}

SOUZA C.; FACCO D. S.; PIRES C. A. F., BENEDETTI A. C.; Mapeamento da Dinâmica do Uso e Cobertura da Terra no Município de Pinhal Grande - RS. V Congresso Brasileiro de Geoprocessamento, 2014.

IBGE. INSTITUTO BRASILEIRO DE GEOGRAFIA E ESTATÌSTICA; Malha Digital Contínua, 2010.

SOUZA, J. R.; REIS, L. N. G.; Mapeamento e Análise do Uso dos Solos no Município de Ibiá - MG Utilizando o Software SPRING 5.1.8: Análise da Dinâmica Agropecuária. OBSERVATORIUM: Revista Eletrônica de Geografia, v.3, n.8, p.141-163, dez.2011. 